\title{
COMMUNICABLE DISEASES REPORT, NEW SOUTH WALES, FOR MAY AND JUNE 2006
}

For updated information, including data and facts on specific diseases, visit www.health.nsw.gov.au and click on Infectious Diseases.

\section{TRENDS}

Tables 2 and 3 and Figure 1 show reports of communicable diseases received through to the end of May and June 2006 in NSW.

\section{MEASLES UPDATE}

The NSW measles outbreak that began with 10 cases in March 2006 and continued through April (29 cases) and May (16 cases) appears to have subsided, with two cases with onset in June. The most recently confirmed case (a young woman from South Eastern Sydney) was reported with onset in early June 2006.

Measles continues to circulate in many parts of the world; therefore outbreaks associated with infectious travellers are likely to continue to occur from time to time while people remain susceptible. Susceptible people are primarily those born after 1965 who have not received two doses of the measles, mumps and rubella (MMR) vaccine. Opportunistic promotion of vaccination for susceptible people (for example, during health checks before overseas travel) continues to be an important prevention strategy. The early notification of cases to the local public health unit assists in the early containment of outbreaks.

\section{ENTERIC DISEASES}

\section{An outbreak of Clostridium perfringens food poisoning}

In May 2006, the NSW Food Authority referred a complaint of food borne disease to the Liverpool office of the Sydney South West Area Health Service. The complainant reported that 70 of 90 people who attended a catered function at a community hall became sick with diarrhoea 7 to 14 hours after the function. The complainant was reluctant to provide any contact details of ill people as some family members had prepared food for the function. A number of Indian dishes including curries and rice were provided by a restaurant and family members. The NSW Food Authority tested some leftover food samples. One of the chicken curry samples from the restaurant was positive for Clostridium perfringens.

Clostridium perfringens occurs widely in the environment. C. perfringens food poisoning is caused by a toxin produced by the bacteria. Symptoms of C. perfringens poisoning are abdominal cramps and diarrhoea, usually without vomiting, occurring 6 to 24 hours after the meal. Most people recover within a day. Almost all outbreaks are caused by inadequately heated or reheated meat, particularly meat in casseroles, pies and gravies. Whilst we were unable to interview cases associated with this outbreak, a number of the features of this outbreak are classical for C. perfringens: the symptoms, the high attack rate, a catered event, the transport of food and subsequent reheating in a community hall, and confirmation of $C$. perfringens in the food sample.

\section{Salmonellosis}

There was an increase in salmonellosis caused by Salmonella Typhimurium PT 135 a in May, with 11 cases reported compared with an average of four for May for the last five years. Interviews with cases did not reveal any common source.

Salmonellosis is caused by an infection with Salmonella bacteria. In Australia, most salmonellosis cases occur after eating contaminated food or occasionally after contact with another person or an animal infected with Salmonella. People with salmonellosis commonly develop headache, fever, abdominal cramps, diarrhoea, nausea and vomiting. Symptoms start 6 to 72 hours after infection and usually last 4 to 7 days, sometimes longer.

Approximately 2000 cases of salmonellosis are reported annually in NSW. In the last year or so, NSW and other Australian states have conducted a number of epidemiological investigations to examine the increases in notifications of particular Salmonella serovars. OzFoodNet, a national network for enhancing food borne disease surveillance and investigation, has coordinated many of the national studies. A number of exposures associated with increased risk for salmonellosis have been identified, including certain bakery products, alfalfa sprouts, and contact with ornamental fish, but most commonly the consumption of under-cooked chicken or eggs and their by-products. ${ }^{1-3}$

Thorough cooking of food kills Salmonella. Avoid raw or undercooked meat, poultry or eggs. Poultry and certain prepared meats - such as hamburgers, sausages, and rolled roasts-should not be eaten if pink in the middle.

Doctors, hospitals and laboratories must notify outbreaks of food borne disease to the local public health unit. The public health unit can advise on who should be excluded from work and school. Children in childcare should stay home for 24 hours after their diarrhoea has stopped. People who are food handlers or who care for children, the sick or the elderly, should avoid work for 48 hours after their diarrhoea has stopped.

If you have a complaint about a food business please contact the NSW Food Authority on 1300552406.

\section{References}

1. The OzFoodNet Working Group. OzFoodNet: enhancing food borne disease surveillance across Australia: Quarterly report, 1 October to 31 December 2005. Commun Dis Intell 2006; 30: 148-53. 
2. The OzFoodNet Working Group. OzFoodNet: Quarterly report, 1 January to 31 March 2006. Commun Dis Intell 2006; 30: 228-32.

3. Musto J, Kirk M, Lightfoot D, Combs BG, Mwanri L. Multidrug resistant Salmonella Java infections acquired from tropical fish aquariums, Australia 2003-04. Commun Dis Intell 2006; 30: 222-7.

\section{PERTUSSIS IN A NURSERY}

In June 2006, a pathology laboratory notified Sydney West Area Health Service of a case of pertussis in an 11-weekold infant. The infant had been an inpatient in the neonatal intensive care unit during the period that they acquired the infection. The public health unit initiated a search for possible sources of the infection and found that a number of staff members in the unit and special care nursery had had recent coughing illnesses. Seven health care workers were subsequently diagnosed with pertussis following clinical review and pathology testing. Another staff member who had symptoms was epidemiologically linked to the cluster. Based on the dates of cough onset and the common work places of the cases, at least three generations of disease transmission were identified in this outbreak.

Cases that were infectious were treated and excluded from work and all clinical staff working in the affected wards were given antibiotic prophylaxis to avert further infections. Unimmunised health care workers were offered pertussis booster vaccination. Other neonates who may have been exposed were given antibiotic prophylaxis. Surveillance for cough was instituted in staff, parents and babies.

This outbreak is an important reminder that many heath care workers are susceptible to pertussis and may transmit it to vulnerable patients. A single booster immunisation is recommended for all health care workers caring for infants and children. Health care workers who have a persistent cough should be investigated and, if necessary, treated for pertussis.

\section{OUTBREAK OF A RESPIRATORY ILLNESS IN A RURAL TOWN IN SOUTHERN NEW SOUTH WALES IN FEBRUARY 2005}

\section{Kym Bush and Lisa Clarkson}

Greater Southern Public Health Unit

Greater Southern Area Health Service

\section{James Branley}

\section{Nepean and Blue Mountains Pathology Service}

In February 2005 the Greater Southern Public Health Unit was notified by a local general practitioner from a rural town (population 4300) of eight people presenting with fever, dry cough and breathlessness in the preceding four weeks. Five of these cases had radiological evidence of pneumonia. The outbreak began during the week of the annual agricultural show and following the migration of a large number of black cockatoos into the area, raising concerns that it was caused by a zoonotic infection such as psittacosis or Q fever. The Greater Southern Public Health Unit investigated this apparent outbreak to identify its extent and possible cause.

\section{Investigation}

Patients with a diagnosis of atypical pneumonia were identified by contacting general practitioners from the surrounding area and reviewing the local hospital's inpatient and outpatient data.

A case was defined as any person from the area who presented with fever and cough and one other symptom with onset between 28 January and 7 March 2005.

In a case series study, the Greater Southern Public Health Unit interviewed cases using a standardised questionnaire to obtain information on demographics, any potential exposures to animals, onset and nature of symptoms, occupation, and laboratory tests.

Nose and throat swabs were collected from cases and couriered to the reference laboratory for psittacosis polymerase chain reaction (PCR), direct immunofluorescence for respiratory viruses and viral culture. Acute and convalescent serology (four weeks later) for antibodies to Mycoplasma pneumoniae, Legionella, Chlamydophila psittaci, Coxiella burnetii, adenovirus, and influenza $\mathrm{A}$ and $\mathrm{B}$ virus were also collected. Individuals with a fourfold or greater rise in antibody titre were considered as being recently infected. Urinary antigen for Legionella pneumophila and Streptococcus pneumoniae were also collected.

A site visit to the area was conducted and environmental samples (feathers, droppings, etc) from within the local showground and bird pavilions were collected for psittacosis PCR. Organisers of the local agricultural show were interviewed regarding the assortment of animals that had been brought into the area for the weekend prior to the start of the outbreak. Local veterinarians, council staff, National Parks and Wildlife staff and Wildlife Rescue Service workers were interviewed to determine whether there had been any sick or injured birds recently.

\section{Results}

Nineteen potential cases were identified through reporting by general practitioners and review of hospital inpatient and outpatient data for the five-week study period. Of these, 17 were interviewed. The remaining two, who had onset of symptoms on 28 January and 3 February 2005, were itinerant workers and could not be contacted. One potential case was diagnosed with asthma-associated pneumonia by a local paediatrician and was excluded.

The remaining 16 cases were included in the study. A review of the previous year's presentations to the hospital revealed that only three to four presentations of atypical pneumonia could be expected per month.

There were equal numbers of males and females. Four cases (25 per cent) were hospitalised and six cases (38 per cent) had pneumonia confirmed by chest $x$-ray. The age range of cases was 3 to 65 years (median -22 years, mean -26 years). Six cases were in children less than 11 years old. There appeared to be family clustering of cases, with two to four cases in each of two families. Fever 
and cough were reported by all cases. Other signs and symptoms were breathlessness (81 per cent), arthralgia (69 per cent), headache (56 per cent), malaise (38 per cent), sore throat (25 per cent), rales (25 per cent) and nausea (19 per cent).

Mycoplasma IgM was positive in three cases. Bordetella pertussis was detected by whole cell IgA EIA in one case. Seven paired sera were tested but one pair was anticomplementary and was unable to be tested. A fourfold rise in antibody titre was seen in one of the paired sera for Chlamydophila psittaci. One case had a persistently raised Q fever phase 2 antibody. All nose and throat swabs were culture negative. All nose and throat swabs and environmental swabs were Chlamydia PCR negative (for both genus and psittaci specific).

\section{Discussion}

It appears that this cluster of respiratory illness was due to several different infections, possibly including mycoplasmosis, pertussis, psittacosis and Q fever, and did not have a common cause. Initial concerns of a zoonotic outbreak linked to the annual agricultural show or black cockatoos were not substantiated.

Previously reported outbreaks of psittacosis have been associated with aviaries, pet shops or poultry processing plants and also linked to wild birds. ${ }^{1,2}$ Psittacine birds such as parrots, cockatiels and parakeets that are infected with C. psittaci can spread the bacteria in droppings and in dust contaminated with infected droppings. The organism can remain viable in the environment and humans can then inhale the bacteria, causing infection. ${ }^{2}$

The setting of this outbreak shares some important characteristics with the Blue Mountains area, where an outbreak of psittacosis occurred in 2002. ${ }^{2}$ It is high in altitude (approximately 1000 metres above sea level), surrounded by bushland and relatively sparsely populated by humans. This outbreak also had commonalities with the initial outbreak of community-acquired psittacosis in Bright, Victoria in $1995 .{ }^{1}$ To help exclude psittacosis as the diagnosis in this investigation we used psittacosis PCR rather than serologic diagnosis of chlamydial infections, which lack specificity. These results were available within days of the commencement of the investigation. It is of note that there were also features of this outbreak that made psittacosis less likely as the diagnosis: the family clustering and the involvement of children as well as the equal sex distribution were not features of the previous outbreaks and suggested a pathogen that was transmitted from human-to-human.

Despite the lack of a unifying diagnosis, this investigation was important for allaying concerns of the community and highlighted the use of more rapid diagnostic modalities such as PCR and antigen detection to help exclude pathogens in an outbreak setting.

\section{References}

1. Williams J, Tallis G, Dalton C, Ng S, Beaton S, Catton M et al. Community outbreak of psittacosis in a rural Australian town. Lancet 1998; 351: 1697-9.

2. Telfer BL, Moberley SA, Hort KP, Branley JM, Dwyer DE, Muscatello DJ et al. Probable psittacosis outbreak linked to wild birds. Emerg Infect Dis (serial on the internet). March 2005. Available from: www.cdc.gov/ncidod/EID/ vol11no03/04-0601.htm. Accessed 8 October 2006.

\section{QUARTERLY REPORT: AUSTRALIAN CHILDHOOD IMMUNISATION REGISTER}

Table 1 compares the percentages of fully immunised Indigenous and non-Indigenous children in NSW aged 12 months to less than 15 months in each area health service, reported by all service providers.

These data refer to children whose age has been calculated 90 days before data extraction. The information contained in the report has been extracted from the Australian Childhood Immunisation Register and may be underestimated by approximately three per cent due to children being vaccinated late, or to service providers failing to forward information to the Australian Childhood Immunisation Register. 용

\section{TABLE 1}

PERCENTAGE OF FULLY IMMUNISED CHILDREN AGED 12 MONTHS TO LESS THAN 15 MONTHS, BY AREA HEALTH SERVICE, AND BY INDIGENOUS AND NON-INDIGENOUS STATUS, FOR DECEMBER 2005 TO JUNE 2006

\begin{tabular}{|c|c|c|c|c|c|c|}
\hline & \multicolumn{2}{|c|}{$31 / 12 / 2005$} & \multicolumn{2}{|c|}{$31 / 03 / 2006$} & \multicolumn{2}{|c|}{$30 / 06 / 2006$} \\
\hline & $\begin{array}{c}\text { Non-Indigenous } \\
\%\end{array}$ & $\begin{array}{c}\text { Indigenous } \\
\%\end{array}$ & $\begin{array}{c}\text { Non-Indigenous } \\
\%\end{array}$ & $\begin{array}{c}\text { Indigenous } \\
\%\end{array}$ & $\begin{array}{c}\text { Non-Indigenous } \\
\%\end{array}$ & $\begin{array}{c}\text { Indigenous } \\
\%\end{array}$ \\
\hline \multicolumn{7}{|l|}{ Area Health Service } \\
\hline Greater Southern & 94 & 91 & 92 & 78 & 91 & 83 \\
\hline Greater Western & 90 & 85 & 90 & 83 & 90 & 79 \\
\hline Hunter / New England & 93 & 86 & 93 & 84 & 93 & 87 \\
\hline North Coast & 86 & 83 & 85 & 80 & 85 & 83 \\
\hline Northern Sydney / Central Coast & 91 & 97 & 90 & 95 & 91 & 88 \\
\hline South Eastern Sydney / Illawarra & 91 & 90 & 90 & 95 & 91 & 86 \\
\hline Sydney South West & 89 & 89 & 90 & 82 & 89 & 78 \\
\hline Sydney West & 90 & 84 & 89 & 90 & 90 & 79 \\
\hline NSW & 91 & 88 & 90 & 84 & 90 & 83 \\
\hline AUSTRALIA & 91 & 86 & 90 & 85 & 91 & 84 \\
\hline
\end{tabular}


FIGURE 2

\section{REPORTS OF SELECTED COMMUNICABLE DISEASES, NSW, JAN 2001 TO MAY 2006, BY MONTH OF ONSET}

Preliminary data: case counts in recent months may increase because of reporting delays.

Laboratory-confirmed cases only, except for measles, meningococcal disease and pertussis $\mathrm{BFV}=$ Barmah Forest virus infections

RRV = Ross River virus infections

Lab conf $=$ laboratory confirmed
Men $\mathrm{Gp} \mathrm{C}$ and $\mathrm{Gp} \mathrm{B}=$ meningococcal disease due to serogroup $C$ and serogroup $B$ infection, other/unk = other or unknown serogroups.

NB: multiple series in graphs are stacked, except gastroenteritis outbreaks.

NB: Outbreaks are more likely to be reported by nursing homes and hospitals than by other institutions

\begin{tabular}{|lr}
\hline \multicolumn{2}{|l|}{ NSW population } \\
Male & $50 \%$ \\
$<5$ yrs & $7 \%$ \\
$5-24$ yrs & $27 \%$ \\
$25-64$ yrs & $53 \%$ \\
$65+$ yrs & $13 \%$ \\
Rural & $46 \%$
\end{tabular}

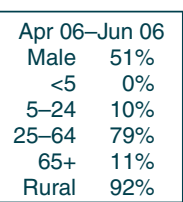

Rural $92 \%$

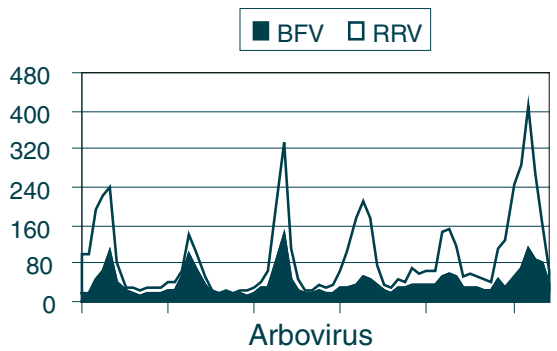

\begin{tabular}{|rr|}
\hline \multicolumn{2}{|c|}{ Apr 06-Jun 06 } \\
Male & $46 \%$ \\
$<5$ & $39 \%$ \\
$5-24$ & $18 \%$ \\
$25-64$ & $42 \%$ \\
$65+$ & $1 \%$ \\
Rural & $40 \%$ \\
\hline
\end{tabular}

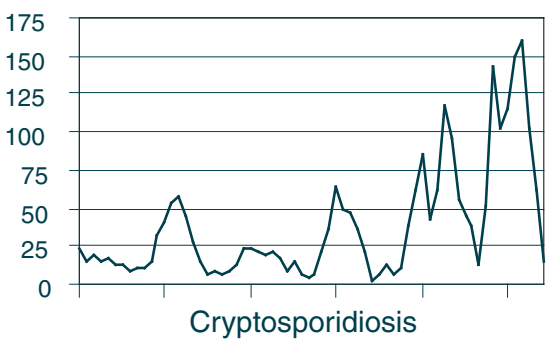

\begin{tabular}{|rr|}
\hline \multicolumn{2}{|c|}{ Apr 06-Jun 06 } \\
Male & $83 \%$ \\
$<5$ & $0 \%$ \\
$5-24$ & $32 \%$ \\
$25-64$ & $68 \%$ \\
$65+$ & $0 \%$ \\
Rural & $15 \%$ \\
\hline
\end{tabular}
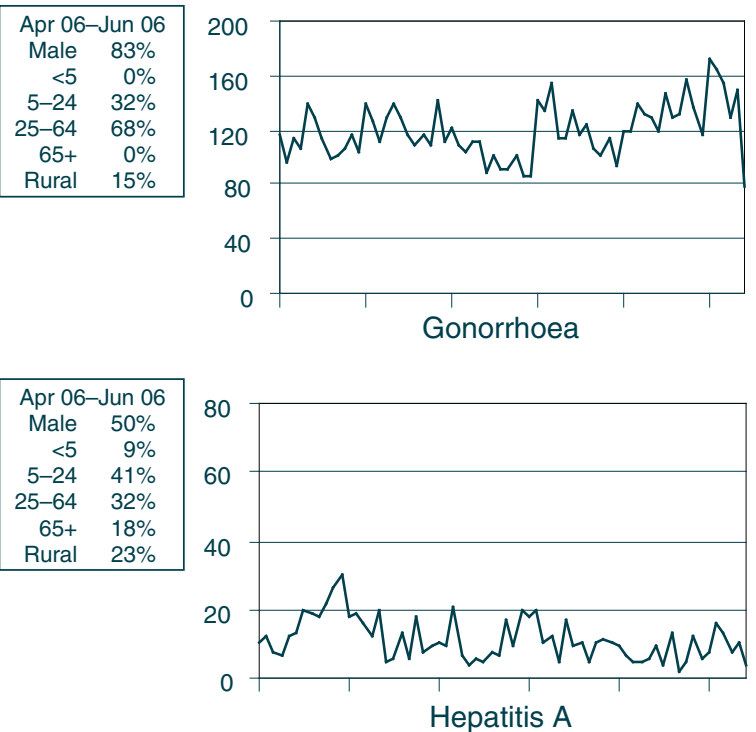

\begin{tabular}{|lr|}
\hline \multicolumn{2}{|c|}{ Apr 06-Jun 06 } \\
All outbreaks & 144 \\
Nursing homes & 100 \\
Hospitals & 25 \\
Child care & 18 \\
Schools & 0 \\
Other & 1 \\
\hline
\end{tabular}

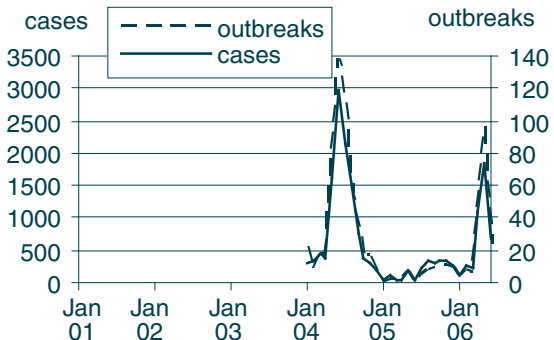

Gastroenteritis outbreaks in institutions

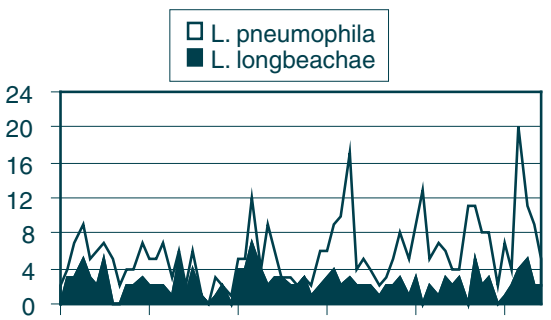

\begin{tabular}{|cc|}
\hline \multicolumn{2}{|c|}{ Apr 06-Jun 06 } \\
Male & $68 \%$ \\
$<5$ & $0 \%$ \\
$5-24$ & $0 \%$ \\
$25-64$ & $44 \%$ \\
$65+$ & $56 \%$ \\
Rural & $32 \%$ \\
\hline
\end{tabular}

Legionellosis

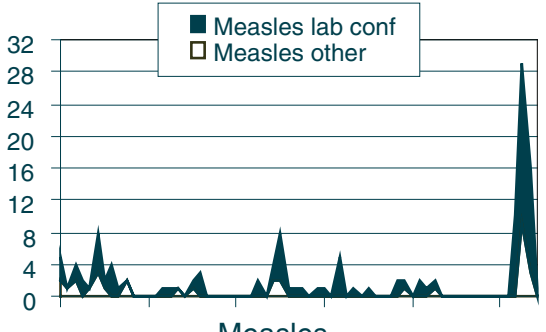

\begin{tabular}{|rc|}
\hline \multicolumn{2}{|c|}{ Apr 06-Jun 06 } \\
Male & $35 \%$ \\
$<5$ & $33 \%$ \\
$5-24$ & $37 \%$ \\
$25-64$ & $30 \%$ \\
$65+$ & $0 \%$ \\
Rural & $13 \%$ \\
\hline
\end{tabular}

Measles

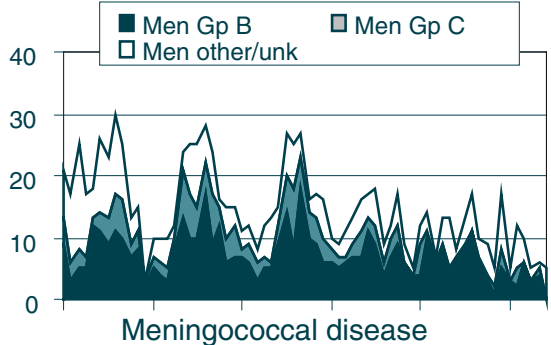

\begin{tabular}{|rc|}
\hline \multicolumn{2}{|c|}{ Apr 06-Jun 06 } \\
Male & $38 \%$ \\
$<5$ & $44 \%$ \\
$5-24$ & $37 \%$ \\
$25-64$ & $19 \%$ \\
$65+$ & $0 \%$ \\
Rural & $25 \%$ \\
\hline
\end{tabular}

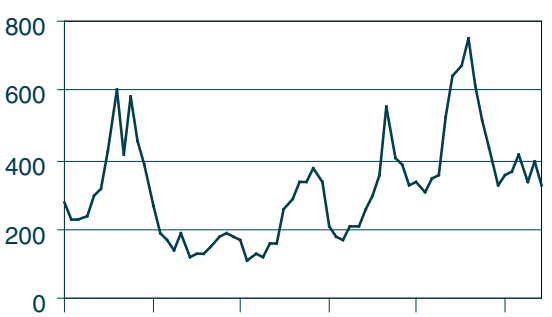

Pertussis

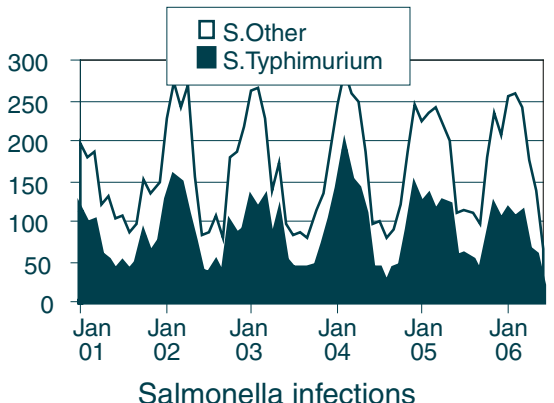




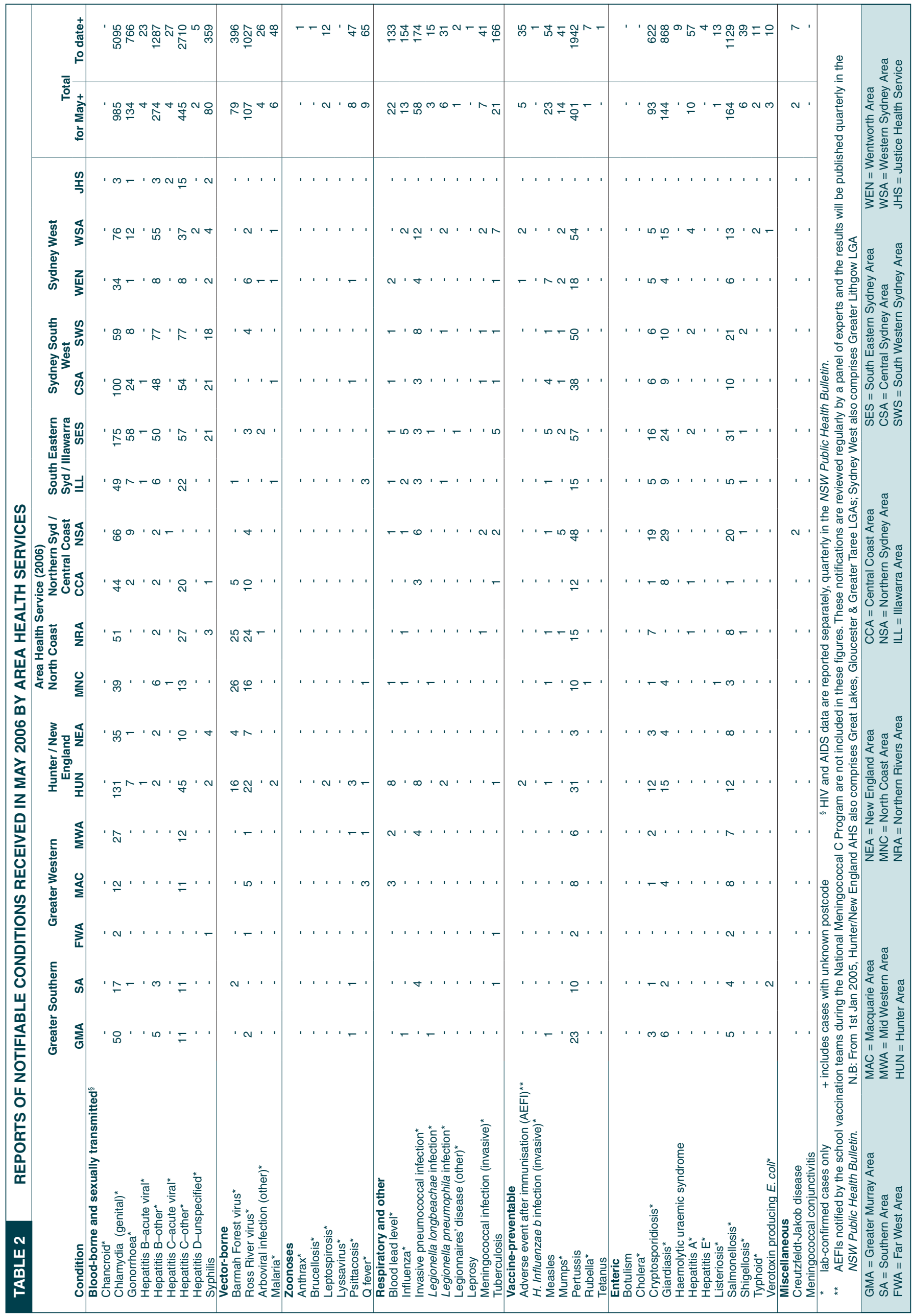




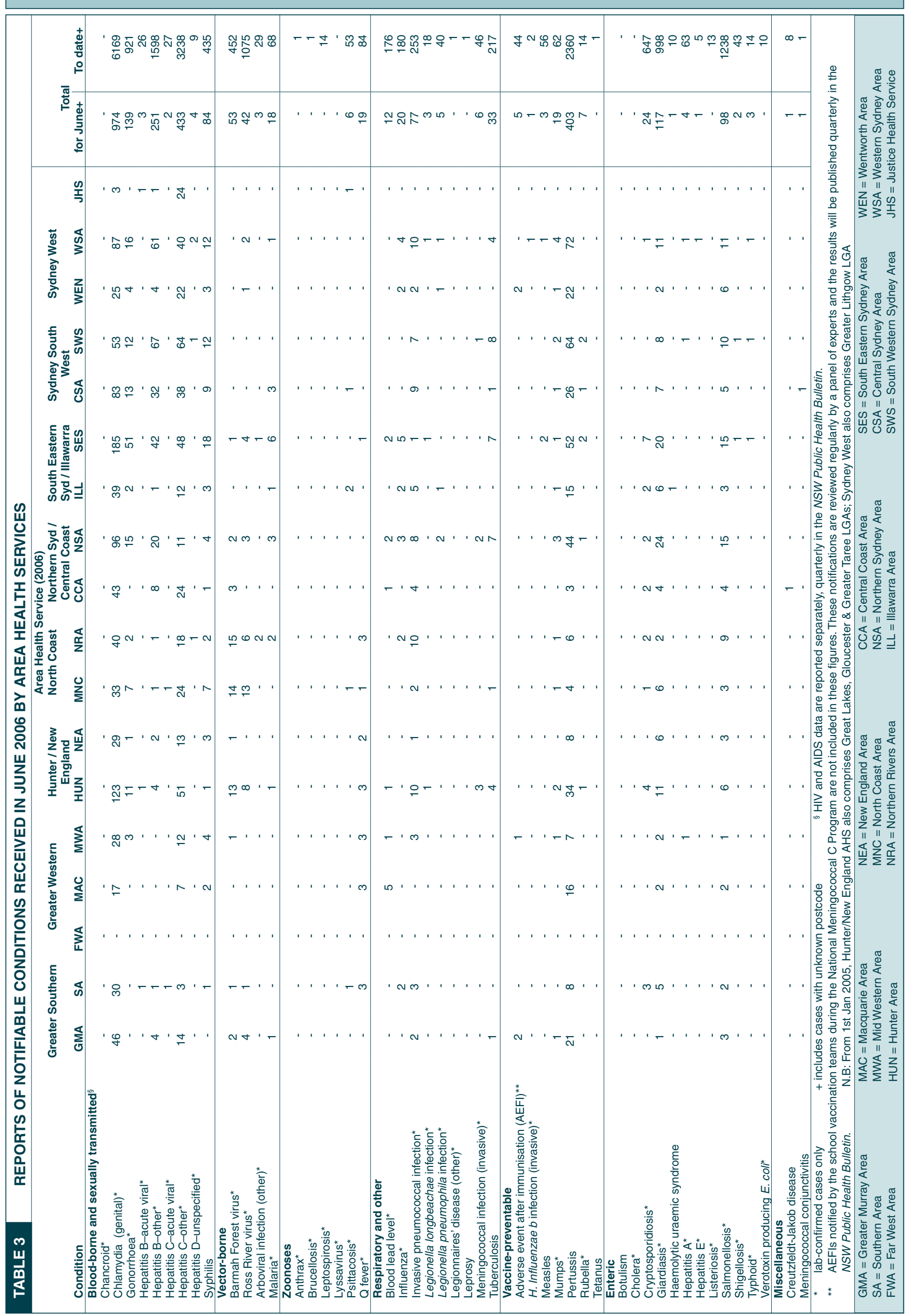

